\title{
Reflexos da globalização na cultura alimentar: considerações sobre as mudanças na alimentação urbana
}

\author{
Effects of globalization on food culture: considerations \\ on urban food changes
}

Rosa Wanda Diez GARCIA

\section{R E S U M O}

A comensalidade contemporânea é aqui discutida, focalizando particularmente o impacto nas mudanças alimentares urbanas, fundamentando-se em autores das ciências sociais que discutem a globalização. Abordou-se o processo pelo qual alimentos e serviços são desterritorializados e alcançam um caráter global, visando contribuir para estudos sobre as mudanças alimentares e analisar outras dimensões, além das nutricionais, do que se denomina dieta afluente.

Termos de indexação: dieta afluente, práticas alimentares, alimentação urbana, cultura alimentar.

\section{A B S T R A C T}

This paper evaluates the contemporary commensalism focusing particularly upon the impact on urban food changes, based on social science authors who discuss the globalization. It approaches the process whereby foods and services are deterritorialized and achieve a global character, in order to contribute to studies of food changes and to analyze other dimensions of the so-called affluent diet.

Index terms: affluent diet, feeding practices, urban food, food culture.

\footnotetext{
1 Faculdade de Nutrição, Centro de Ciências da Vida, PUC-Campinas. Av. John Boyd Dunlop, s/n. Prédio Administrativo, Jd. Ipaussurama, 13059-900, Campinas, SP, Brasil.
} 


\section{DEMANDAS PARA UMA NOVACOMENSALIDADE}

A comensalidade contemporânea é o foco de interesse deste artigo que pretende discutir como se configuram algumas mudanças nas práticas alimentares urbanas.

Em decorrência de novas demandas geradas pelo modo de vida urbano, ao comensal é imposta a necessidade de reequacionar sua vida segundo as condições das quais dispõe, como tempo, recursos financeiros, locais disponíveis para se alimentar, local e periodicidade das compras, e outras. As soluções são capitalizadas pela indústria e comércio, apresentando alternativas adaptadas às condições urbanas e delineando novas modalidades no modo de comer, o que certamente contribui para mudanças no consumo alimentar.

Produto deste modus vivendi urbano, a comensalidade contemporânea se caracteriza pela escassez de tempo para o preparo e consumo de alimentos; pela presença de produtos gerados com novas técnicas de conservação e de preparo, que agregam tempo e trabalho; pelo vasto leque de itens alimentares; pelos deslocamentos das refeições de casa para estabelecimentos que comercializam alimentos - restaurantes, lanchonetes, vendedores ambulantes, padarias, entre outros; pela crescente oferta de preparações e utensílios transportáveis; pela oferta de produtos provenientes de várias partes do mundo; pelo arsenal publicitário associado aos alimentos; pela flexibilização de horários para comer agregada à diversidade de alimentos; pela crescente individualização dos rituais alimentares.

O comportamento alimentar é complexo, incluindo determinantes externos e internos ao sujeito. O acesso aos alimentos, na sociedade moderna, predominantemente urbana, é determinado pela estrutura socioeconômica, a qual envolve principalmente as políticas econômica, social, agrícola e agrária. Assim sendo, as práticas alimentares, estabelecidas pela condição de classe social, engendram determinantes culturais e psicossociais.

Apesar dos contrastes econômico e sociocultural entre países pobres e ricos, as tendências observadas através de estudos epidemiológicos sobre consumo alimentar, assinalam a reprodução de características similares, ou seja, o padrão alimentar antes característico dos países desenvolvidos é atualmente uma preocupação também dos países em desenvolvimento. Esta constatação foi produto de uma reunião de especialistas em Dieta, Nutrição e Enfermidades não Transmissíveis da Organização Mundial da Saúde, que aconteceu em Genebra em 1989. Isto leva a supor a existência de pressões condicionantes destas tendências.

Influenciadas pelos avanços tecnológicos na indústria de alimentos e na agricultura e pela globalização da economia, as práticas alimentares contemporâneas têm sido objeto de preocupação das ciências da saúde desde que os estudos epidemiológicos passaram a sinalizar estreita relação entre a dieta - afluente - e algumas doenças crônicas associadas à alimentação, motivo pelo qual o setor sanitário passou a intervir mudanças nos padrões alimentares.

A adoção da dieta "afluente", caracterizada por um excesso de alimentos de grande densidade energética, ricos em gordura e em açúcar refinado simples, e por uma diminuição no consumo de carboidratos complexos (fonte importante de fibras alimentares), tem se expandido, sobretudo em situações de prosperidade econômica ${ }^{1,2}$. Quando se diz que a ascensão econômica de um país se reflete no padrão de consumo alimentar e conseqüentemente no perfil de morbi-mortalidade, deve-se buscar entender como e porque a prosperidade econômica atinge as diferentes culturas em uma mesma direção. As mudanças no padrão alimentar devem ser entendidas por seus aspectos objetivos e subjetivos, levando-se em consideração a urbanidade como contexto da comensalidade contemporânea.

A globalização da economia e a industrialização exercem um papel importante, 
devido à gama de produtos e serviços distribuídos em escala mundial e ao suporte publicitário envolvido. Uma tendência crescente para o consumo de alimentos de maior concentração energética é promovida pela indústria de alimentos através da produção abundante de alimentos saborosos, de alta densidade energética e de custo relativamente baixo ${ }^{3}$. A globalização atinge a indústria de alimentos, o setor agropecuário, a distribuição de alimentos em redes de mercados de grande superfície e em cadeias de lanchonetes e restaurantes. A difusão da ciência nos meios de comunicação e o uso do discurso científico na publicidade de alimentos também exercem seu papel no cenário das mudanças alimentares. Embora nos países mais pobres estas tendências de consumo estejam distribuídas diferentemente nos segmentos de classes sociais de acordo com as possibilidades de acesso aos bens de consumo, no plano simbólico os desejos de consumo por si só marcam uma inclinação a este perfil alimentar.

A estandardização de certas instâncias das práticas e do comportamento alimentar facilitam as mudanças na alimentação que vão sendo incorporadas como parte do modo de vida, como conseqüência deste. Pressionadas pelo poder aquisitivo, pela publicidade e praticidade, as práticas alimentares vão se tornando permeáveis a mudanças, representadas pela incorporação de novos alimentos, formas de preparo, preparo, compra e consumo.

Contudo, é possível que tais mudanças encontrem mais ou menos resistência, dependendo da cultura alimentar e da consolidação de suas práticas estabelecidas e simbolicamente valorizadas.

A permeabilidade de uma dada cultura alimentar a novas práticas é um aspecto a ser analisado levando-se em conta componentes da própria cultura. De acordo com Renato Janine Ribeiro o vazio de nossa origem, relatada como país subalterno, dependente, colonizado, influi na definição de nossa identidade 4 . Enquanto outras nações se perguntam para onde irão, nós nos perguntamos quem somos. Todavia, ao perceber que raiz, origem, identidade são construídas, este vazio passa a ser um trunfo pela liberdade em relação à raiz, manifestada em uma idéia de nacionalidade a qual o autor se refere como "quase antropofágica", no sentido de integrar o outro. Participando desta mesma discussão a respeito do país, Freire Costa destaca a rapidez e a facilidade com que o brasileiro absorve itens das culturas americana e européia por serem consideradas modos de vida "superiores" pelos que se julgam "inferiores" 4

Para Dória $(2002)^{5}$ a nossa culinária, composta pelas culturas indígenas e pelas heranças negra e ocidental ibérica, são por analogia, três línguas diferentes, três sistemas culinários irredutíveis uns aos outros e ainda desconhecemos de fato nosso repertório culinário dos últimos 500 anos por falta de interesse das elites dominantes, cujos olhares sempre se voltaram para a Europa e, mais recentemente, para os Estados Unidos, em uma perspectiva de imitação, reservando desprezo pelo nativo. Ao instigar uma gastronomia sustentada na criação e redescoberta dos sabores brasileiros, o autor coloca como desafio renovar a culinária de uma estrutura formada por sistemas culinários distintos.

Este suposto caráter permeável da nossa cultura resultaria, pois, em uma capacidade de importar novas práticas e gostos, de gerar novas demandas, de assumir prontamente mudanças no modo de vida e de abandonar aqueles costumes e práticas que poderiam conformar uma identidade própria. Sejam quais forem as explicações para as mudanças sofridas nas práticas alimentares, é certo que elas engendram um novo padrão alimentar.

\section{O caráter global de alimentos e serviços}

No início da década de 90, com a abertura de mercado, houve um crescimento considerável nas importações de alimentos no Brasil. No período de 1992 a 1995 a importação de produtos 
alimentares industrializados cresceu 409\%. O maior aumento foi observado nas preparações alimentícias diversas (1193\%), no cacau e em outras preparações à base de cacau (1237\%) e em preparações à base de cereais (538\%). A importação de leite e derivados cresceu 970\% e a de bebidas, líquidos alcoólicos e vinagre cresceu $640 \%{ }^{6-9}$.

Segundo a empresa de pesquisa de mercado Datamark Ltda - Market Intelligence(2), a qual se utiliza da produção de embalagens para suas estimativas, houve um incremento importante na produção de iogurtes e outras bebidas lácteas entre 1990 e 1996: as bebidas lácteas tiveram um aumento de $829 \%$ e os iogurtes líquidos, de $252 \%$, correspondendo, respectivamente, a um crescimento de 60730 e 70688 toneladas, respectivamente. Os embutidos, principalmente a salsicha e a lingüiça, durante a década de 80 , tiveram sua produção duplicada e, até 1996, multiplicada por 2,8 e 2,3, respectivamente, totalizando uma produção anual de 221588 toneladas de salsichas e 238866 toneladas de lingüiça. Os alimentos congelados, um exemplo de produtos que poupam serviço e facilitam o trabalho doméstico, cresceram $126 \%$ no período de 1990 a 1996 (totalizando em 1996 uma produção de 46141 toneladas). Em 1980 eram produzidas 20095 toneladas de salgadinhos industrializados; em 1996 esta produção foi 6,2 vezes maior. A produção de refrigerantes e cerveja cresceu, nos últimos dez anos, $90 \%$ e $76 \%$, respectivamente. De 1990 a 1996 a produção de biscoito aumentou $108 \%$ e a de cereais em flocos, $426 \%$.

A opção por facilidades que poupam tempo de preparo e diminuem a freqüência das compras é característica do comensal urbano contemporâneo, como se pode notar ao analisar o tipo de leite consumido - enquanto a produção do leite longa vida cresceu de 184 para 1782 toneladas entre 1990 e 1996, o leite pasteurizado teve sua produção reduzida, passando de 4243 toneladas em 1990 para 2779 em 1996.
De acordo com os resultados do Estudo Multicêntrico sobre Consumo Alimentar (EMCA) ${ }^{10}$, trabalho mais recente com a preocupação em traçar um perfil do consumo alimentar, realizado em cinco cidades brasileiras (Campinas, Curitiba, Goiânia, Ouro Preto e Rio de Janeiro), os 16 alimentos mais consumidos (aqueles que fornecem até $80 \%$ da energia total disponível) em ordem decrescente de prioridade em todas as faixas de renda apresentaram variações por nível salarial e entre os municípios estudados. No município de Campinas, por exemplo, o refrigerante, a bolacha doce e a salsicha estão entre os principais itens que garantem o aporte energético. Comparando os principais alimentos que contribuíram para o aporte energético de duas faixas de renda extremas; ainda exemplificando dados do município de Campinas, na primeira faixa (até meio salário mínimo per capita) o arroz, óleo, açúcar, feijão, leite e macarrão foram os alimentos mais consumidos; já para a última faixa de renda (entre 10 e 15 salários mínimos per capita) estes alimentos foram: pão de forma, arroz, óleo, açúcar, pão francês e leite. Enquanto o arroz e o feijão ocuparam a primeira e quarta posição de prioridade para os indivíduos de renda menor, para os mais abastados estes alimentos estavam, respectivamente, em segundo e décimo segundo lugar. A diferença por nível salarial expressa a redução no consumo de alimentos tradicionais, como o arroz e o feijão, pelas famílias de renda maior; além disso, a crescente presença de alimentos industrializados com peso na ingestão energética nas diferentes faixas de renda expressa mudanças na alimentação em direção à dieta afluente.

A evolução do consumo alimentar no Brasil pode ser observada nas pesquisas: Estudo Nacional de Despesa Familiar (ENDEF) ${ }^{11}$, Pesquisa de Orçamentos Familiares 1987/88 12 e Pesquisa de Orçamentos Familiares 1995/1996 ${ }^{13}$.

Ao comparar o $\mathrm{EMCA}^{10} \mathrm{com}$ o ENDEF ${ }^{11}$, pode-se notar a presença de novos produtos

2 Os dados apresentados foram fornecidos pela própria empresa e são referentes ao período de 1986 a 1996. 
industrializados de peso na dieta brasileira, como refrigerantes, macarrão, bolacha doce e salgada, leite condensado, margarina, salsicha, leite em pó, maionese, chocolate e pão de forma.

A Pesquisa de Orçamento Familiar (POF) de 1995-199613, traz alguns resultados interessantes sobre as modificações no consumo de alimentos nos últimos dez anos. Comparando com o POF de 1987-1988, a distribuição de gastos por itens demonstrou uma redução nas despensas com carnes frescas e vísceras (de 17,13\% para $12,97 \%$ ), cereais, leguminosas e oleaginosas (de $5,56 \%$ para $4,22 \%$ ) e açúcares e derivados (de 4,44\% para 3,40\%). Os panificados (pão francês, biscoitos e outros) e os alimentos preparados ou semi-prontos aumentaram seu peso no orçamento familiar. Apesar da redução dos gastos com carnes frescas e vísceras, o consumo de alimentos fontes de proteína animal cresceu: o consumo de frango aumentou $16,56 \%$; de carne bovina de primeira, 5,97\%; e de carne de segunda, 6,95\%. Houve um declínio no consumo de alimentos fornecedores de carboidratos complexos: o consumo de arroz polido e de farinha de trigo foi reduzido em $16,56 \%$ e $29,73 \%$, respectivamente. Outros alimentos que tiveram seu consumo reduzido foram o feijão $(-15,56 \%)$ e o leite de vaca $(-19,31 \%)$. Alguns alimentos tiveram comportamento diferenciado por região. O consumo de macarrão cresceu em Curitiba (30,12\%) e Brasília $(21,06 \%)$ e diminuiu em Belo Horizonte (-24,26\%), Recife $(-23,31 \%)$ e Fortaleza $(-22,27 \%)$. Ao contrário do decréscimo no consumo de leite no Brasil, Belém apresentou aumento de 86,29\%. Também o consumo de farinha de trigo, feijão e arroz foi diferenciado por região.

Além do consumo crescente de alimentos industrializados, outros canais implementam a cultura alimentar globalizada no Brasil, tais como o aumento da comercialização de alimentos feita através de rede de supermercados de grande superfície. No Brasil, em 1998 27,8\% da comercialização de alimentos era feita através de hipermercados e a expectativa era de crescimento, com previsão para chegar a 35\% em cinco anos pelas principais empresas do ramo: Carrefour, Pão de Açúcar, Bom Preço, Casas Sendas e Paes Mendonça ${ }^{14}$.

Ortiz (1994) ${ }^{15}$ trata da emergência de uma sociedade global onde processos globais transcendem os grupos, as classes sociais e as nações. Ele aborda as transformações no âmbito da cultura, apesar de tratar também de aspectos políticos e econômicos. Encara a globalização como um processo em construção, distinto do processo de internacionalização, mais antigo, que vem a ser um aumento da extensão geográfica das atividades econômicas através das fronteiras nacionais. A globalização da economia constitui uma forma mais avançada e complexa da internacionalização, envolvendo um certo grau de integração funcional entre atividades econômicas dispersas. Aplica-se à produção, distribuição e consumo de bens e serviços, organizados a partir de uma estratégia internacional, voltada para o mercado mundial. Considera, portanto, que a cultura mundializada está fundamentada nas transformações de ordem estrutural. Apesar de reconhecer a dimensão econômica e as relações estabelecidas com o universo cultural, ressalta que não se pode circunscrevê-lo a qualquer tipo de determinismo.

A formação desta sociedade modifica substancialmente as condições de vida e trabalho, os modos de ser, sentir, pensar e imaginar. As características da globalização configuram uma sociedade universal, promovem o deslocamento de coisas, indivíduos e idéias, desenraízam e promovem uma desterritorialização generalizada ${ }^{16}$. Segundo lanni a desterritorialidade é uma característica essencial da sociedade global, já que as estruturas de poder econômico, político, social e cultural são internacionais, mundiais, descentradas, não dispondo de uma localização física.

A visão de ambos os autores acerca do processo de globalização abarca elementos objetivos e subjetivos da sociedade. Pensar em aspirações, utopias, imaginação, enquanto elementos difusos em escala global, pode ajudar 
a refletir sobre a imposição de valores relacionados aos alimentos, à saúde e ao corpo, bem como sobre as tendências de consumo alimentar que acompanham o desenvolvimento econômico e, portanto, estão associados à internacionalização da economia e aos processos de globalização.

Há, na produção e no consumo, um caráter cosmopolita. Quanto mais afluente se torna uma sociedade, maiores necessidades vão sendo criadas pelo mesmo processo em que são satisfeitas. As necessidades dependem da produção, podendo surgir antes mesmo dela, através da publicidade ou do marketing ${ }^{16}$.

Para Ortiz (1994) ${ }^{15}$ " uma cultura mundializada não implica o aniquilamento das outras manifestações culturais, ela co-habita e se alimenta delas". Não há identificação entre mundialismo e uniformidade. lanni (1993) ${ }^{16}$ também caracteriza a sociedade global pelo convívio do homogêneo e do plural.

Conceber a cultura mundializada como uma civilização cuja territorialidade foi globalizada não significa considerá-la homogênea. O que ocorre é a estandardização de diferentes instâncias da vida moderna, produto do industrialismo que penetra nos diferentes setores da sociedade. A padronização da sociedade, decorrente do consumo, torna-se um processo hegemônico no mundo atual, mas sem implicar uniformização. Ortiz ${ }^{15}$ defende haver, além das particularidades, um padrão - pattern - que pertence à cultura mundializada. Os processos de produção, estilização e pasteurização transformam a mercadoria em produto desejável para diferentes nacionalidades. O público absorve padrões, estilos, modas, os quais são difundidos como mercadorias globais. Neste sentido pode-se dizer que existe uma instância de caráter homogêneo.

De acordo com Fischler (1995) ${ }^{17}$ a culinária dos restaurantes estrangeiros faz sua comida típica com o "molho" da cozinha receptora. Estas adaptações, segundo este autor, afetam não apenas os produtos ou os sabores, mas também as estruturas profundas da culinária de origem, sua gramática e sua sintaxe. É possível ainda encarar estas alterações como adaptações às estruturas culinárias do país receptor, ou seja, ao fazer estas modificações são introduzidos novos pratos na culinária do país estrangeiro, preservando algumas características da culinária de origem. Produz-se uma nova versão de um prato. Por exemplo, há a pizza em sua versão original, a italiana, na versão brasileira, na versão norte-americana e assim por diante. Estas versões já foram absorvidas, readaptadas e se desgarraram da original. Porém há uma essência da pizza: a massa, o tomate, o orégano e o queijo. Esta seria, segundo denominou Ortiz ${ }^{15}$, um pattern, um pattern de paladar. Fischler ${ }^{17}$ nomeia esta diluição das características genuínas em benefício do consumo em massa como o "mínimo denominador comum". Há uma retradução dos pratos típicos, os quais sofrem metamorfoses até adequarem-se ao consumidor global.

Um dos pontos que Ortiz (1994) $)^{15}$ considera essencial para discutir a mundialização é a modernidade. Ela está associada à racionalização da sociedade, em seus níveis econômico, político e cultural. Privilegia qualidades como funcionalidade, mobilidade e racionalidade. Pensada deste modo, "a sociedade é um conjunto desterritorializado de relações sociais articuladas entre si".

Para exemplificar a modernidade-mundo o autor analisa a alimentação, pois esta é uma instância cultural que preserva costumes, é um pilar da identidade cultural e traduz a estabilidade do grupo social. Durante o último século, dois movimentos acentuaram o processo de mundialização: a diversificação de produtos e a passagem da cozinha tradicional, com a preparação de pratos típicos, para uma cozinha industrial. Deste modo há um desenraizamento da alimentação. É possível encontrar pratos típicos de qualquer parte do mundo, e os alimentos, que antes eram sazonais nos países desenvolvidos, são agora oferecidos durante todo o ano. A desterritorialização do alimento difunde-o em escala mundial. Cerveja, biscoito, chocolate, refrigerantes pertencem ao mundo. E o que aconteceu com a comida tradicional típica? Ela persiste, mas 
metamorfoseada para adaptar-se à expansão. Perdeu sua peculiaridade. A comida deixa de ter vínculo territorial. Neste sentido tanto faz uma pizza, um hambúrguer ou um croissant, todos perderam suas origens ou sua essência tradicional e, embora mantenham seu valor simbólico, tornaram-se produtos da cozinha industrial.

Para Ortiz (1994) ${ }^{15}$ e também para Fischler $(1995)^{17}$ interessa menos a americanidade do McDonald's do que o fato de exprimir um padrão alimentar adaptado à modernidade, o fast-food. Como o tempo é um elemento-chave no mundo contemporâneo, os fast-foods são ágeis, poupam o tempo de preparo e de ingestão e são deslocáveis para qualquer espaço. Como uma das expressões do movimento de aceleração da vida, os fast-foods não se difundem por seu traço cultural, mas por exprimir a modernidade-mundo. Estabelecimentos como McDonald's, Pizza Hut, Brioche Dore, entre outros, segundo esses autores, não difundem uma cultura alimentar, mas são parte da mundialização no plano alimentar, pois isso não se impõe aos valores autóctones, que já não se opõem aos estrangeiros pela flexibilidade das fronteiras. No entanto, ressalta Fischler (1995) ${ }^{17}$, a América, em muitos domínios, nos campos econômico, social e civilizatório, passou por experiências precoces. As tendências observadas na desestruturação das práticas alimentares foram detectadas nos anos 60s na América. Na Europa, os costumes proíbem, geralmente, a mistura de atividades; por isso as refeições são preservadas, têm um espaço e um tempo reservados e seus deslocamentos aparecem em menor grau nos meios urbanos dos países europeus. Este espaço reservado às práticas alimentares no continente europeu poderia derivar da valorização e do sentimento de pertencimento manifestado na gastronomia, de modo que a alimentação nutre a identidade cultural.

Apesar de os argumentos destes dois autores coincidirem quanto ao fato de a difusão das redes de lanchonetes e restaurantes e da indústria de alimentos não representar a "americanização do mundo", há que se pensar na existência de uma nacionalidade simbólica na propagação destes produtos globalizados. Não há dúvidas de que as facilidades dos fast-foods e sua adequação ao modo de vida urbana sejam fatores cruciais para o seu sucesso. No estudo das representações sociais da comida no meio urbano foi feita esta mesma constatação ${ }^{18}$. Foi observado que as representações sociais deste tipo de lanchonete a consideram vantajosa por sua estrutura automatizada, por seu aspecto moderno, pela organização do seu espaço e pela higiene, mas ela se destaca das outras sobretudo por sua marca, assim como uma roupa de grife é diferenciada de uma semelhante pela etiqueta.

Além de apresentarem esse caráter "moderno", esses produtos são vendidos com uma imagem que os embala, e esta sim tem seu traço de americanidade, podendo ser considerada parte da cultura mundializada. Na difusão de uma imagem, há a emissão de modelos e o norte-americano é um deles, do mesmo modo que o europeu, o qual também parece estar sendo delineado no plano alimentar, através da valorização dos produtos da comunidade européia. No Brasil observa-se a valorização do modelo norte-americano como referência de modernidade, como símbolo do primeiro mundo. A idealização de modernidade referida, representada pelo rótulo "americano", contém as idéias de vanguarda científica, avanço tecnológico, poder econômico, praticidade da vida cotidiana, e outras. O crescimento de lanchonetes norteamericanas no Brasil reflete a adesão ao que representa o "ideal americano". A oitava maior rede de McDonald's do mundo é a brasileira, a qual é também a quinta que mais cresce. Há 187 restaurantes e 86 quiosques da rede em 12 Estados brasileiros. Seu faturamento em 1995 no país totalizou 620 milhões de dólares, representando o atendimento de 235 milhões de pessoas $^{19}$. Enquanto no Brasil se expandem as cadeias de lanchonetes como McDonald's e Pizza Hut, entre outras, nos Estados Unidos, desde a década de 80, McDonald's, Burguer King e outras lanchonetes do gênero encontram dificuldades 
para manter seus patamares de venda e conter seu declínio ${ }^{20}$. Contra elas, há um crescimento de restaurantes de comida italiana, mexicana, chinesa, indicando que os sanduíches e a comida rápida estão perdendo consumidores. Entre os motivos desta mudança estão o interesse por sabores exóticos, por lugares aconchegantes, por produtos saudáveis, preferências do consumidor mais promissor, alvo dos publicitários americanos ${ }^{21}$.

Ianni $(1993)^{16}$ refere-se ao processo de ocidentalização do mundo, originado na Europa e revigorado nos Estados Unidos, cujos signos e emblemas são: progresso, evolução, ordem, modernização, racionalização, tecnificação, europeização, americanização, ocidentalização.

Grácia-Arnaiz (1996)22 estudou a transformação alimentar na Catalunha (Espanha) urbana entre as décadas de 60 e 90, e, ao analisar a publicidade alimentar no referido período, concluiu que o predomínio do modelo norte-americano vigorou entre os anos 70s-80s e nos anos 80s-90s passou a predominar um padrão "europeizado". Na década de 60-70 a publicidade de produtos alimentícios valorizou o "nacional-espanhol", como vinho, batata, arroz. Houve uma incipiente "internacionalização" com a propaganda de produtos como o sal inglês, a margarina norueguesa, as sopas suíças, e outros. Na década seguinte persistiu a valorização do caráter nacional dos produtos, combinado com estrangeirismos como tipo Frankfurt, presunto york, queijo Philadelphia, patês, e outros. Na década de 80-90 as propagandas dos produtos espanhóis divulgaram variedades nativas, como azeites de oliva, vinhos, cavas, queijos, presunto serrano, frutos secos, entre outros. Também apareceram os autonômicos (produtos diferenciados pela origem, como por exemplo os vinhos de Andaluzia, os embutidos de Vic, e outros). Nesta mesma década houve a "europeização", com a valorização da origem dos produtos como atributo de boa qualidade. Na década de 60-70 os anunciantes eram principalmente as empresas nacionais e começava a ser introduzida a publicidade de origem multinacional. Entre 1971 e
1980 houve o assentamento das multinacionais e entre 1981 e 1990 passaram a preponderar os anunciantes destas empresas. Neste período houve um incremento da concentração empresarial e maior diversificação de produtos.

Um outro elemento analisado por Ortiz $(1994)^{15}$, como parte da mundialização da cultura, é o significado de "tradição", imbuído de dois sentidos distintos: a "tradição enquanto permanência do passado distante", com uma forma de organização social contrária à modernização, que representa o mundo anterior à Revolução Industrial, expressada pelas culturas populares da América Latina e por algumas práticas da cultura oriental, entre outras; e a "tradição da modernidade", como uma tradição reinventada, a qual recicla elementos da memória internacional popular, recriando e atualizando elementos do passado que se misturam com o presente. $\mathrm{Na}$ cultura mundializada a "tradição da modernidade" é um valor que sinaliza uma maneira de ser e uma visão de mundo. Passam a ser clássicos o modelo "tradicional" da garrafa de Coca-Cola, os pôsteres de Bogart ou Garbo, entre outros.

Esta concepção de "tradição da modernidade" interessa particularmente para compreender como a cozinha tradicional se reinstala na cultura mundializada. A existência de uma cultura mundializada no padrão alimentar, a qual não se restringe aos produtos industrializados ou aos restaurantes e lanchonetes de rede, é inegável. A noção de "tradição da modernidade" explica as mudanças que ocorrem na estrutura alimentar contemporânea: os pratos tradicionais ou típicos são transferidos para os restaurantes e instituições e, no âmbito doméstico, são preparados ou encomendados (em restaurantes, rotisserias e outros prestadores de serviço) apenas em ocasiões especiais como festividades e comemorações. Estes pratos tradicionais, por sua vez, são readaptados às condições atuais, seja no modo de preparo, seja nos produtos utilizados. Há uma simplificação nos procedimentos culinários e uma adaptação aos valores atuais, entre eles os relacionados à saúde e ao corpo. Por exemplo: a 
feijoada passa a ser feita com partes menos gordurosas do porco - uma adaptação à preocupação com a gordura e a obesidade, a moqueca de peixe passa a ser feita com leite de coco engarrafado, os pratos que demandam uma preparação nos moldes originais como a galinha ao molho pardo, ou ficam localizados nos restaurantes ou são comprados os ingredientes prontos para serem utilizados, sendo pouco provável que a dona de casa mate a galinha, depene-a e processe-a de modo a obter seu sangue para o preparo do molho, procedimento utilizado pelas gerações anteriores.

A valorização do tradicional é observada como o principal argumento na publicidade de alimentos da década de 80-90 e, comparativamente com as duas décadas anteriores, foi o argumento que mais cresceu nas propagandas sobre produtos alimentícios ${ }^{22}$. Por tradicional entendem-se os valores vinculados à natureza, à terra, à origem rural e sua suposta identificação com o "autêntico" e "puro". A referência familiar é a tradicional, associada a práticas domésticas convencionais. É justamente quando cresce a utilização de produtos industrializados que o argumento "tradição" ganha mais destaque. Esta busca pela tradição se enquadra perfeitamente na noção de "tradição da modernidade" assinalada por Ortiz" ${ }^{15}$. É a busca do genuíno simbólico, o qual dará o caráter de "tradicional". Esta tradição é, portanto, metafórica. Em estudo realizado no centro da cidade de São Paulo, com funcionários da Prefeitura Municipal alocados no Edifício Martinelli, também foi observada a valorização pelo gosto "natural", caracterizado pelo "não industrializado", por tudo o que é rotulado como artesanal e pela valorização da produção doméstica. No entanto, o que é chamado de "natural" aparece de modo arbitrário, associado à representação de uma essência "natural"19.

Vários outros autores chamam a atenção para esta contradição ${ }^{17,22,23}$, sendo inclusive um dos motivos para argumentar contrariamente à homogeneidade no padrão alimentar: a valorização das preparações típicas, o resgate de processos artesanais de preparação de certos produtos alimentares. Mas isto não representa, necessariamente, uma volta às origens e sim um resgate do atributo "tradição" como um bom argumento para venda. Mesmo com o resgate de técnicas e procedimentos, a produção é voltada para a promoção do produto, "o típico, preparado artesanalmente", e provavelmente conta, em alguma etapa do processo de preparação, com as facilidades da tecnologia e da modernidade.

O enaltecimento de dietas tradicionais, motivado por interesses sanitários, não é novidade. Passaram a ser recomendadas como modelos de dieta quando indicadores de saúde - expectativa de vida, perfil de morbi-mortalidade - reconheciam melhores resultados em uma dada região. O melhor exemplo disto é a propagação da dieta mediterrânea como ideal24-26. Na verdade, este tipo de reconhecimento do "tradicional" se enquadra melhor naquilo que Ortiz (1994) ${ }^{15}$ chamou de pattern. Neste caso seria a estilização da dieta mediterrânea que produziria um padrão (pattern) de pertencimento à cultura globalizada. Já não seria a dieta mediterrânea, mas um pattern dela, apropriado para exportação e circulação no mundo globalizado.

\section{Dieta afluente ou comensalidade contemporânea}

Se por um lado tal processo de globalização amplia a diversidade alimentar, por outro também a reduz, uma vez que circula um mesmo leque de opções alimentares próprias da globalização. As mudanças na alimentação devem ser entendidas no contexto sociocultural da urbanidade em seus determinantes objetivos e subjetivos. Como as diferentes culturas e, particularmente a nossa irão absorver em seu cotidiano alimentar essa diversidade de padrões (patterns)? Como eles se acomodarão e quais mudanças podem ser provocadas no repertório culinário de referência são questões que merecem ser investigadas para melhor se delinear a comen- 
salidade contemporânea e assim aprofundar o conhecimento sobre os seus determinantes.

\section{A GRADECIMENTOS}

Agradeço ao Sr. Graham Wallis, diretor da Datamark Ltda - Market Intelligence, pela generosidade em ter cedido para consulta seu precioso banco de dados sobre produção de alimentos industrializados.

\section{REFER Ê NCIAS}

1. Organización Mundial de La Salud. Dieta, nutrición y prevención de enfermedades crónicas. Ginebra; 1990. 228p. (Série de Informes Técnicos, n.797).

2. Popkin BM. Urbanization, lifestyle changes and the nutrition transition. World Dev 1999; 27(11):1905-16.

3. Drewnowski A. Nutrition transition and global dietary trends. Nutr 2000; 16(7/8):486-7.

4. Couto JG. Quatro autores em busca do Brasil. Rio de Janeiro: Rocco; 2000. p.31-87.

5. Dória CA. A cozinha subdesenvolvida. Trópico: idéias de Norte a Sul. Disponível em: http:// www.uol.com.br/tropico/ 23/03/2002

6. Instituto Brasileiro de Geografia e Estatística. Anuário Estatístico do Brasil. Brasília; 1993.

7. Instituto Brasileiro de Geografia e Estatística. Anuário Estatístico do Brasil. Brasília; 1994.

8. Instituto Brasileiro de Geografia e Estatística. Anuário Estatístico do Brasil. Brasília; 1995.

9. Instituto Brasileiro de Geografia e Estatística. Anuário Estatístico do Brasil. Brasília; 1996.

10. Instituto Nacional de Alimentação e Nutrição. Estudo multicêntrico de consumo alimentar. Ministério da Saúde: Brasília; 1997.

11. Instituto Brasileiro de Geografia e Estatística. Estudo Nacional da Despesa Familiar - Dados Preliminares. Rio de Janeiro; 1978.

12. Instituto Brasileiro de Geografia e Estatística. Pesquisa de Orçamentos Familiares, 1987 - 1988. Rio de Janeiro; 1991.
13. Instituto Brasileiro de Geografia e Estatística. Pesquisa de Orçamentos Familiares, 1995 - 1996. Primeiros Resultados. Rio de Janeiro; 1997.

14. Folha de São Paulo, 1998. Negócios, 13 de abril de 1998.

15. Ortiz R. Mundialização e cultura. 2.ed. São Paulo: Brasiliense; 1994. 234p.

16. Ianni O. A sociedade global. 2.ed. Rio de Janeiro: Civilização Brasileira; 1993. 194p.

17. Fischler C. El (h)omnívoro- El gusto, la cocina y el cuerpo. Barcelona: Editorial Anagrama; 1995. $421 \mathrm{p}$.

18. Garcia RWD. Práticas e comportamento alimentar no meio urbano: um estudo no centro da cidade de São Paulo. Cad Saúde Pública 1997; 13(2): 455-67.

19. McDonald's. Informe publicitário. São Paulo; 1996. $22 p$.

20. Veja, 16 de outubro de 1996. p.102-4.

21. Meyers W. Los creadores de imagen. 2.ed. Barcelona: Editorial Ariel; 1994. p.13-31, 124-47.

22. Grácia-Arnaiz M. Paradojas de la alimentación contemporánea. Barcelona: Icária -Institut Català d'Ántropologia; 1996. 309p.

23. Carrasco SP. Antropologia i alimentació - Una proposta per l'estudi de la cultura alimentària. Bellaterra: Servei de Publicacions de la Universitat Autònoma de Barcelona; 1992. 124p.

24. Keys A. Mediterranean diet and public health: personal reflections. Am J Clin Nutr 1995; 61 (suppl):1321S-3S.

25. James WPT. Mediterranean diet and public health: implications for Mediterranean diets. Am J Clin Nutr 1995; 61(suppl):1324S-8S.

26. Mataix J. La dieta mediterránea. Dieta tradicional versus dieta recomendada. In: Medina X, editor. La alimentación mediterránea - historia, cultura, nutrición. Barcelona: Icária Antrazyt; 1996. p.269-78.

Recebido para publicação em 23 de março de 2002 e aceito em 8 de janeiro de 2003. 